\title{
Physical foundations of variatropia recipe regulation and control of concrete properties with centrifugal seal
}

\author{
Levon Mailyan, Sergei Stel'makh, Evgenii Shcherban*, Alla Smolyanichenko, and Alina \\ Demidova \\ Don State Technical University, 344000, Rostov-on-Don, Russia
}

\begin{abstract}
The features and mechanisms of the processes occurring during concrete centrifugation are considered. It was found that a significant difference in the centrifugal and centripetal forces acting on the outer, middle and inner layers of the cross-section leads to significant differences in the structure and characteristics of the element layers. The possibility of regulating the variatropia and controlling the concrete properties during centrifugal seal by regulating the prescription factors is considered. The forms of various aggregates' interaction with cement stone and the mixture components' separation features during centrifugation are analyzed. Based on the analysis data, it is proposed to use a combination of various types aggregates and densities in centrifuged concrete. The main types of fibers are identified and the analysis of the effectiveness of their use is carried out. On the basis of the performed analysis, the most promising way of increasing the efficiency of fiber-concrete centrifuged elements was determined, namely, the combination of two or more types of fibers. The most expedient combinations of the aggregates and fibers' types have been identified, which makes it possible to guarantee the directional movement of the components of the concrete mixture during centrifugation. In terms of the aggregate, this is the use of a large aggregate with a high density and a fine aggregate with a lower density, and in terms of fibers, it is a combination of steel and non-metallic fibers.
\end{abstract}

\section{Introduction}

Centrifugation is one of the widespread methods for manufacture of tubular concrete and reinforced concrete structures, providing the simultaneous execution of two technological operations - giving the configuration of the pipe loaded into the form of a concrete mixture as well as concrete mixture seal [1].

The essence of centrifugal molding and seal lies in the fact that when a mold rotates with a concrete mixture uniformly distributed in it around a fixed axis at a certain speed, centrifugal pressure arises, under the influence of which liquid with highly dispersed fractions suspended in it is squeezed out of the cement gel and at the same time larger particles approach solid. As a result of this process, the gel cohesion is increased and the concrete mixture seal is achieved [2-5].

The ability of the concrete mixture to be evenly distributed over the inner surface of the rotating mold is determined by the viscoplastic properties of the cement gel. If to place

\footnotetext{
*Corresponding author: au-geen@mail.ru
} 
viscoplastic or short-term vibration-liquefied concrete mixture into a rotating mold, then under the action of centrifugal radially directed pressure, it will begin to deform - spread out in all directions. This will continue until there is an equilibrium between the forces promoting the mixture distribution in the mold and the structural resistance to the cement gel compression. With an increase in the rotation speed of the form, the liquid phase will begin to be squeezed out of the cement gel and will continue until the sealed mixture acquires the properties of a pseudo-solid [6-9].

The centrifugal pressure is directly perceived by the liquid phase, in connection with which the excess hydrostatic pressure increases, under the influence of which the liquid is filtered and at the same time the concrete mixture is sealed. As a result, the compressibility of the cement gel decreases and an equilibrium state is established, characterized by an internal redistribution of pressure and the cessation of the filtration process due to significant resistance to the movement of fluid through the pore tubules [10].

During centrifugation and vibro-centrifugation of elements with a sufficiently thick wall, the centrifugal and centripetal forces acting on the outer, middle and inner layers of the cross section differ greatly, which leads to a significant difference in the structure and characteristics of the element layers, which should be taken into account during the calculations.

Therefore, the possibility of regulating the variatropia and controlling the properties of concrete during centrifugal seal by regulating the recipe factors will be considered.

\section{Methods and materials}

The quality of the aggregate in concrete of a given strength is determined mainly by the mechanical properties of these components. In assessing the quality of the filling part of concrete, a complex of characteristics plays an important role: the value of the specific surface of the grains; porosity; particle texture, etc. An important component of a concrete stone is contact layers, which have an additional effect on the conglomerate strength.

The adhesion strength of the contact layer reflects the qualitative state of the adsorbedsolvating shell and the nature of the physical and chemical interaction of the contacted components. In this case, the adhesive contact degree will, in particular, be determined by the filler type.

So, adsorption on the surface of granite grains in a cement slurry proceeds without any chemical interaction, and therefore the adhesive strength of such a joint will be low, which is confirmed by concrete destruction at the contact between the faces of the aggregate and the cement stone. The contact of cement stone with quartz usually has the form of a blurred strip $[11,12]$.

The contact zone becomes noticeably wider in the samples that harden for a long time under normal conditions or undergo heat treatment. The chemical interaction of cement stone with quartz and the formation of fine-crystalline calcium hydro-silicate seals the contact and increases the adhesion strength. A light porous aggregate actively participates in the concrete structure formation, which, absorbing a certain part of moisture (up to $30 \%$ ) from the mortar component, gives it back upon further hardening of concrete, creating a "microclimate" in the concrete mixture. In contrast to heavy concrete, the contact zone of the porous aggregate with the mortar is formed by a sealed shell of cement stone, devoid of sedimentation pores. As noted by G.A. Buzhevich, porous aggregate contributes to significant unloading of the cement casing and relieves the stresses arising in it from shrinkage. Consequently, in lightweight structural concrete, the level of internal stresses is less than in heavy concrete. A small difference in the values of temperature deformations of lightweight aggregate and cement stone is one of the factors increasing the frost resistance of such concretes. The accumulation of irreversible residual deformations, other things 
being equal, occurs here more slowly and, mainly, due to cracking in the mortar part of lightweight concrete with the retention of contacts between the filler and cement stone [13].

Taking into account the indicated forms of interaction of various aggregates with cement stone and the peculiarities of the separation of the components of the mixture during centrifugation, it should be assumed that the use of aggregates combination of various densities and types in centrifuged concrete will improve not only its layer-by-layer homogeneity, but also increase the strength and durability of the conglomerate.

But this does not apply to the elements made of vibro-centrifuged concrete, in which vibration will enhance separation and, as a result, variatropia.

And here the problem of regulating the properties of concrete by prescription factors, depending on the goal, arises. If the goal is to obtain as much variatropic concrete as possible, then here the effect of prescription factors, in particular the complex use of aggregate types of the entire spectrum of density and strength (heavy, lightweight and light) in combination with technological factors - the use of vibro-centrifugation with the most effective modes in terms of variatropy - will lead to such concrete production, in which the gradient of variatropia by the layers will be the most significant - and the properties and characteristics of the outer, middle and inner layers of concrete will differ as much as possible.

If the goal is to obtain as homogeneous concrete as possible, that is, the least variatropic, then it is advisable either not to use combinations of aggregate types of the entire spectrum of density and strength, or to use them, but in combination with technological factors that do not enhance, but reduce variatropia.

Various metallic and non-metallic fibers are used for fiber reinforcement of concrete.

As a metal fiber, a thin wire with a diameter of $0.1 \ldots 0.5 \mathrm{~mm}$, chopped into pieces of 10 ... $50 \mathrm{~mm}$, is usually used. The best results are provided by fibers with a diameter of 0.3 $\mathrm{mm}$ and a length of $25 \mathrm{~mm}$, and with an increase in diameter over $0.6 \mathrm{~mm}$, the effectiveness of the dispersed reinforcement action on the concrete strength decreases sharply.

Glass, basalt, asbestos, polymer and other fibers are used from non-metallic fibers.

The main properties of various types of fibers are shown in the table 1 .

Table 1. Properties of various fibers

\begin{tabular}{|c|c|c|c|c|c|}
\hline Fiber type & $\begin{array}{c}\text { Diameter, } \\
\mathrm{mm}\end{array}$ & $\begin{array}{c}\text { Density, } \\
\mathrm{g} / \mathrm{cm}^{3}\end{array}$ & $\begin{array}{c}\text { Tensile } \\
\text { strength, } \\
\mathrm{hPa}\end{array}$ & $\begin{array}{c}\text { Elastic } \\
\text { modulus, } \\
\mathrm{hPa}\end{array}$ & $\begin{array}{c}\text { Relative } \\
\text { extension, \% }\end{array}$ \\
\hline Steel & $0.1-1.0$ & 7.8 & $0.3-2.0$ & 200 & $0.5-3.5$ \\
\hline Polypropylene & $0.02-0.4$ & 0.9 & $0.3-0.5$ & 5 & $15-25$ \\
\hline $\begin{array}{c}\text { Glass } \\
\text { (alkali-resistant) }\end{array}$ & $0.05-0.15$ & 2.5 & $1.0-3.0$ & $70-80$ & $1.5-4.5$ \\
\hline $\begin{array}{c}\text { Based on } \\
\text { polyvinyl alcohol }\end{array}$ & $\begin{array}{c}0.003- \\
0.014\end{array}$ & 1.3 & $0.7-1.5$ & $12-40$ & $2-3$ \\
\hline Carbon & $0.008-0.01$ & 1.9 & $1.0-3.0$ & $230-400$ & $0.5-1.0$ \\
\hline Basalt & $0.001-$ & 2.6 & $1.6-3.2$ & $70-90$ & $1.4-3.6$ \\
\hline
\end{tabular}

If steel fibers are usually reinforced with heavy concrete, then, as a rule, fine-grained concrete, sometimes cement stone, are reinforced with non-metallic fibers.

The effectiveness of the influence of various types of fibers on the properties of concrete depends on the ratio of the elastic moduli of the fibers $E_{f}$ and concrete $E_{b}$. With respect $E_{f} / E_{b}>1$ it is possible to obtain fiber concretes with increased tensile strength and crack resistance, with $E_{f} / E_{b}<1$ - with increased impact strength and abrasion resistance with increased impact strength and abrasion resistance. 


\section{Results}

In practical construction, the most widespread is steel fiber with a length of $20 \ldots 120 \mathrm{~mm}$, a diameter of $0.5 \ldots 1.2 \mathrm{~mm}$. To improve adhesion to concrete, the fiber is made in a wave form, specially profiled or straight with bent ends. Steel fibers are introduced into the concrete mixture, usually in the amount of $1-2.5 \%$ of the concrete volume (3-9\% by weight, which is $170 \ldots 200 \mathrm{~kg}$ of fiber per $1 \mathrm{~m}^{3}$ mixes).

Steel fibers are sufficiently well anchored in concrete and prevent the development of shrinkage cracks at the initial stage of the mixture hardening. Steel-fiber concrete has a significant number of advantages over concrete with traditional reinforcement compressive strength increases by $10 \ldots 50 \%$, axial tension by $10 \ldots 40 \%$, impact strength 10-12 times, crack resistance - 3 times $[14,15]$.

Glass fibers have a diameter of the order of several tens microns, a length of $20 \ldots 40$ $\mathrm{mm}$. They have high tensile strength and a deformation modulus higher than that of cement stone. However, glass quickly collapses under the action of the alkaline environment of cement, therefore, it is necessary to provide for the use of binders or special measures that protect the destruction of glass fibers in concrete from corrosion - the use of alumina cement, additives in concrete, binding alkalis, impregnation of concrete with a polymer.

Glass fibers are significantly damaged and lose strength, because they are subjected to impacts and abrasion during the movement of aggregate particles during mixing and seal [16].

Asbestos fibers in concrete mix are less damaged by various influences in the factory, but their short length (up to $5 \mathrm{~mm}$ ) and a lower length-to-diameter ratio significantly reduce the quality of reinforcement. Asbestos fibers have high strength and fire resistance, resistance to aggressive alkalis, durability.

Carbon fibers are the most effective in extreme chemical, temperature and fire conditions. But they are still too expensive, and reducing their cost is a matter of the future. With a higher modulus of carbon fiber elasticity compared to the cement stone elasticity modulus, the composition elasticity modulus is significantly increased. When the carbon fibers are oriented parallel to the stress direction, this increase will be up to $50 \%$ with a fiber content of $3 \%$ by volume [17].

In recent years, basalt fiber with a diameter of $20 \ldots 500$ microns and a length of $1 \ldots$ $150 \mathrm{~mm}$ has become widespread in concrete. Basalt fiber has very high chemical resistance - $100 \%$ resistance to water, $96 \%$ to alkali, $94 \%$ to acid. The elastic modulus of the fiber is within $7 \ldots 60 \mathrm{hPa}$, the tensile strength is $600 \ldots 3500 \mathrm{MPa}$ [1].

Basalt fiber increases crack resistance by 3 times, splitting strength by 2 times, impact strength by 5 times, which makes it possible to effectively use it in the construction of earthquake-resistant structures, explosion-proof facilities and military fortifications, as well as for the structures of radio-transparent constructions of complex shapes [6, 11].

Basalt fiber has high adhesion to cement stone and does not require additional fiber configuration changes. Cement stone and basalt fiber have the same coefficient of thermal expansion as metal fiber. Reinforcement with basalt fiber increases the plasticity of concrete and reduces the formation of shrinkage cracks, in contrast to steel mesh $[12,15]$.

Despite the variety of used dispersion-reinforced concretes, in the issue of preventing the formation and development of cracks, the leading role is given to mixed types of fibers.

There are two approaches to this problem. The first is to use fibers of the same type, but different sizes. The second is the use of two or more types of fiber, in particular, a mixture of steel and synthetic fibers.

Based on the analysis performed, it can be stated that the most promising way to increase the efficiency of fiber-concrete elements lies in the direction of combining two or 
more types of fibers, in particular, steel and non-metallic fibers, provided that an effective technology for manufacturing elements is obtained.

The effectiveness of the fibers use in concrete depends on their content and the distance between them. In particular, dispersed reinforcement quite effectively stops the development of hair cracks only when the distance between different fibers is not more than $10 \mathrm{~mm}$.

Let us consider the first elements of concrete with coarse aggregate and steel fiber.

The use of steel fibers with a certain stiffness in concrete, in combination with the use of a coarse aggregate, which does not allow the fibers to be located sufficiently close to each other (Fig. 1), reduces the efficiency of fiber reinforcement in the stretched zone, which leads to an insufficient increase in the parameters of crack resistance and deformability, by which are mainly influenced with the characteristics of the tensile zone concrete.

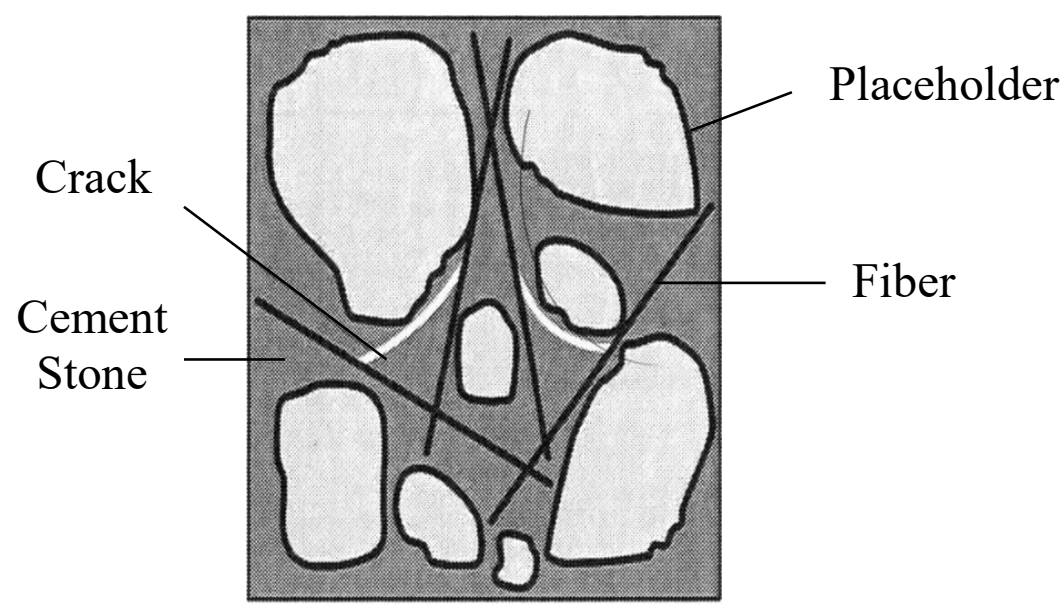

Fig. 1. Steel fiber application in concrete

At the same time, we note that the use of steel fibers with a certain stiffness in concrete, in combination with a large aggregate that does not allow the fibers to be located sufficiently close to each other, has a positive effect on the strength parameters, which mainly depend on the characteristics of the concrete in the compressed zone.

Thus, the use of steel fibers in concrete in combination with a large aggregate leads, on the whole, to a significant increase in the efficiency of the compressed zone and to a much less efficient one in the work of the tensioned zone. Accordingly, in concrete elements with a large aggregate and steel fibers, the bearing capacity (strength) significantly increases and deformability (deflections, curvature) and crack resistance (the moment of formation and width of crack opening) increase significantly.

Let us now consider the elements made of concrete with fine-grained aggregate and non-metallic fibers.

The use of non-metallic fibers in concrete, which have flexibility rather than stiffness, in combination with the use of a fine-grained aggregate, will allow the fibers to be located quite close to each other (Fig. 2). This will increase the fiber reinforcement efficiency in the stretched zone, which will lead to a significant increase in the crack resistance and deformability parameters, which are mainly influenced by the concrete characteristics in the stretched zone. 


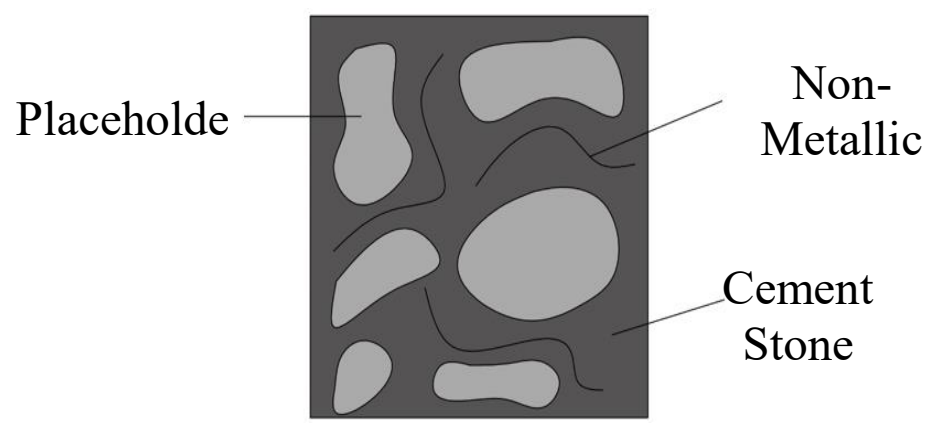

Fig. 2. Application of non-metallic fibers in concrete

At the same time, the use of flexible non-metallic fibers in concrete in combination with a fine-grained aggregate will not significantly affect the strength parameters, which mainly depend on the characteristics of the concrete in the compressed zone.

Thus, the use of non-metallic fibers in concrete in combination with a fine-grained aggregate, leads on the whole, to the opposite picture - a significant increase in the efficiency of the stretched zone and to a much less effective one - the operation of the compressed zone. Accordingly, in concrete elements with a fine-grained aggregate and nonmetallic fibers, the deformability (deflections, curvature) and crack resistance (the moment of formation and width of crack opening) increase noticeably, and the bearing capacity (strength) is significantly less.

Thus, the prospect of obtaining effective structures with a combination of types of aggregate and types of fibers is clearly outlined - in the compressed zone it is advisable to have concrete with coarse-grained aggregate and steel fiber, and in the stretched zone concrete with fine-grained aggregate and non-metallic fiber.

With conventional technologies for producing reinforced concrete elements, in particular vibration, this goal would remain just a beautiful idea or image.

But with centrifugation technologies, and even more so with vibro-centrifugation, the goal becomes quite achievable [18-20].

Imagine a formwork (form) of a vibro-centrifuged element of a circular or a ring-type cross-section, into which concrete mixture is laid, including, in addition to a binder (cement), fine aggregate (sand) and water, a combined aggregate - coarse and fine-grained and a combined fiber - steel and non-metallic.

The formwork (form) begins to vibrate centrifuged, under the influence of centrifugation, enhanced by vibration, the concrete mixture components begin to move inside the formwork (form) - grains of coarse-grained aggregate and steel fibers, as having a large mass, move to the outside of the formwork (form), grains of fine-grained aggregate and non-metallic fibers, as having a lower mass, move to the inside of the formwork (mold).

It should be noted here that, in principle, grains of both coarse and fine-grained aggregates can potentially move in the same direction if they have the same density. To avoid this, it is advisable to take the density of the fine-grained aggregate significantly lower than the density of the coarse-grained aggregate, then the movement of the components of the concrete mixture in the process of vibration centrifugation in the desired direction will be guaranteed.

\section{Discussion}

It can be stated that the most promising way to increase the efficiency of fiber-reinforced concrete elements lies in the direction of combining two or more types of aggregate, in 
particular, coarse and fine-grained, subject to obtaining an effective technology for manufacturing elements.

To obtain rational fiber concretes, it is necessary to match the types of concretes and fibers in their properties and characteristics, more specifically, the compatibility of their strength, deformation and other indicators.

At the same time, most researchers, when choosing the compatible types of concrete and fibers, as a rule, are guided only by common sense, without conducting special research on this matter.

Let us single out three groups of concretes from the whole variety, differing in density and strength - light (up to $1000 \mathrm{~kg} / \mathrm{m}^{3}$ and up to $10 \mathrm{MPa}$, respectively), lightweight (up to $1800 \mathrm{~kg} / \mathrm{m}^{3}$ and up to $25 \mathrm{MPa}$ ) and heavy (up to $2500 \mathrm{~kg} / \mathrm{m}^{3}$ and up to $50 \mathrm{MPa}$ ).

From lightweight concrete, we single out non-autoclave-hardened foam concrete, which has lower costs, short installation and start-up times of technological lines and the availability of a raw material base.

Of lightweight concretes, we will focus on expanded clay concrete, which is characterized by a smooth, rolled shape of a large aggregate, which makes it possible to preserve any kind of fiber almost without breaking and clumping.

From heavy concrete, we will take ordinary heavy concrete with granite crushed stone and sand of normal size.

We distinguish 3 types of fibers for reinforcing concrete, noted above - synthetic (polypropylene fiber), basalt (coarse basalt fiber) and steel (steel fiber).

From the point of view of common sense and logic, the most rational combinations of concrete and fiber types will be:

- heavy concrete with steel fiber;

- lightweight concrete with basalt fiber;

- lightweight concrete with polypropylene fiber.

However, the above-presented logical conclusions require serious experimental confirmation.

\section{Conclusion}

The performed analysis showed that the most promising approach to regulating variatropia and controlling the concrete properties by recipe factors during centrifugation consists in combining types of aggregate and combining types of fibers while ensuring that the types of aggregate and fibers match each other.

Relevant combinations of the aggregate and fiber types have been identified, which makes it possible to guarantee the directional movement of the concrete mixture components during centrifugation:

- in the part of coarse aggregate - coarse-grained aggregate with high density and finegrained aggregate with lower density;

- - in the part of fibers - steel and non-metallic fibers

\section{References}

1. T. Ayub, S.M. Asce, N. Shafiq, S.U. Khan, J. Mater. Civ. Eng. 28, 4 (2016)

2. X. Shen, E. Brühwiler, Cem. Concr. Res. 132 (2020)

3. C. Gu, S. Zhao, W. Sun, Production of precast UHPFRC pavement cover plates in high-speed railway construction (International Symposium on UHPFRC, Marseille, 2013) 
4. C. Zhang, C. Shi, Z. Wu, X. Ouyang, K. Li, Cem. Concr. Res. 125 (2019)

5. P. Iyer, S.Y. Kenno, S. Das, J. Mater. Civ. Eng. 27, 11 (2015)

6. A.B. Kizilkanat, N. Kabay, V. Akyüncü, S. Chowdhury, A.H. Akça, Constr. Build. Mater. 100 (2015)

7. A Hajiesmaeili, E Denarié, Cem. Concr. Res. 143 (2021)

8. F. Sultangaliyeva, H. Carré, C. La Borderie, W. Zuo, E. Keita, N. Roussel, Cem. Concr. Res. 138 (2020)

9. R.T. Dutka, Bulletin of the Odessa State Academy of Construction and Architecture 52 (2013)

10. M.E. Arslan, Constr. Build. Mater. 114 (2016)

11. M. Kharun, D.D. Koroteev, P. Dkhar, S. Zdero, S.M. Elroba, Struct. Mech. Eng. Constr. Build. 14, 5 (2018)

12. F. Elgabbas, E.A. Ahmed E.A., Benmokrane B., J. Compos. Constr. 21, 3 (2016)

13. T. Jirawattanasomkul, T. Ueda, S. Likitlersuang, D. Zhang, N. Hanwiboonwat, N. Wuttiwannasak, K. Horsangchai, Constr. Build. Mater. 223 (2019)

14. V. Fiore, T. Scalici, G. Di Bella, A. Valenza, Composites Part B 74 (2015)

15. L. Teng, W. Meng, K.H. Khayat, Cem. Concr. Res. 138 (2020)

16. S.A. Stel'makh, E.M. Shcherban, A.K. Sysoev, Mater. Sci. Eng. 753, 2 (2020)

17. M.Sh. Salamanova, S.A. Aliev, S-A.Yu. Murtazaev, M.S. Saidumov, I.A. Gabazov, Mater. Sci. Eng. 905 (2020)

18. S.A. Stel'makh, E.M. Shcherban, A.K. Sysoev, Mater. Sci. Eng. 753, 2 (2020)

19. S.A. Stelmakh, A.I. Shuyskiy, E.M. Shcherban, A.Y. Prokopov, Mater. Sci. Forum 974 (2020)

20. E.M. Shcherban, A.Y. Prokopov, S.A. Stelmakh, A.I. Shuyskiy, Mater. Sci. Forum 974 (2020) 